\title{
Influence of Weft Knitted Fabrics Construction for Protection against Ultraviolet Radiation
}

\author{
Ahmed Ali Salman ${ }^{1}$, Z. M. Abdel-Megied ${ }^{2}$, Dr. Nahla .Abd El-Mohsen .H .A ${ }^{3}$, Manar Y. Abd El-Aziz ${ }^{4}$ \\ ${ }^{1}$ Helwan University, Faculty of Applied Arts, Dokki, Giza, Egypt \\ ${ }^{2}$ National Research Centre, Textile Research Division, Dokki, Giza, Egypt. \\ ${ }^{3}$ Helwan University, Faculty of Applied Arts, Dokki, Giza, Egypt. \\ ${ }^{4}$ National Research Centre, Textile Research Division, Dokki, Giza, Egypt
}

\begin{abstract}
Clothing and shade structures provide protection from the deleterious effects of ultraviolet radiations. Suitable construction parameters of fabrics and absorbers or finishing methods can be employed as UV protection fabrics. This study is trying to find a solution for this problem by studying the Influence of weft knitted fabrics Construction with its' different parameters for Protection against Ultraviolet Radiation. This study will stress on knitted fabrics because knitted fabrics of all kinds are generally popular because of their flexibility, ability to adapt as well as stretch them to a particular shape when worn, and because of their general comfortable wear.
\end{abstract}

Key word: UV Radiations, UV Protective Clothing, UPF, Weft Knitted Fabrics Construction

\section{Introduction}

\subsection{Definition of UV Radiations}

Ultraviolet radiation is a sun radiant energy coming from the sun emits, arrange of energy known as electromagnetic spectrum [1], which can be described by two major theories, the wave and the quantum or corpuscular theory. There is a relation between the radiations' wavelength, frequency and its velocity. The basic elements of the quantum theory of light are energetic packets known as photons. Ultraviolet radiation is a light with high energy and short wavelength [2], [3]. Sunlight is a form of electromagnetic radiation in the form of ultraviolet (UV), visible, and infrared radiation [4] with spectrum extends from $290 \mathrm{~nm}$ to $3000 \mathrm{~nm}$.Ultraviolet radiations is just about $7 \%$ of total solar emission with spectrum extends from $290 \mathrm{~nm}$ to $400 \mathrm{~nm}$.[2], [4].

\subsection{Categories of Ultraviolet Radiations}

1) UV-A (320-400 $\mathbf{~ n m ) : ~ U V - A ~ r a y s ~ a r e ~ t h e ~ l e a s t ~ p o w e r f u l ~ o f ~}$ the UV rays, but it can penetrate deeply in to the skin and contribute to premature aging of the skin and skin cancers [1].

2) UV-B (280-320 $\mathbf{n m})$ : UV-B rays are the most powerful and potentially harmful form of radiation.

3) UV-C (200-280 $\mathbf{~ n m ) : ~ U V - C ~ r a y s ~ a r e ~ t h e ~ s h o r t e s t ~ a n d ~ t h e ~}$ most powerful of the UV rays, UV-C is the most likely to cause cancer if it reaches skin. Fortunately, most of it is absorbed by the ozone layer in our atmosphere $[1,5,6]$. So the order of potency has been decided as UVC $>$ UVB $>$ UVA [7].

\subsection{Definition of sun protective clothing, SPF and UPF}

The definition of a sun protective fabric is a fabric that must achieve a minimum UV Protection Factor (UPF) rating of at least UPF15 after the equivalent of 2 years of normal wear and tear. UPF is similar to SPF (sun protection factor) used to rate sunscreens but UPF is the rating used to measure the amount of UV rays that pass through fabrics when exposed to UV radiation [8]. The Ultraviolet Protection Factor (UPF) of a fabric is a quantitative measurement of the effectiveness of the fabric to protect the human skin against ultraviolet radiation [9].

Table 1: UPF Rating [10].

\begin{tabular}{|c|c|c|}
\hline UPF & \% UV Radiation absorbed & Protection category \\
\hline 10 & 90.0 & Moderate \\
\hline 15 & 93.3 & Good \\
\hline $\mathbf{2 0}$ & $\mathbf{9 5 . 0}$ & Good \\
\hline $\mathbf{3 0}$ & $\mathbf{9 6 . 7}$ & Very good \\
\hline $\mathbf{4 0}$ & $\mathbf{9 7 . 5}$ & Excellent \\
\hline $\mathbf{5 0}$ & $\mathbf{9 8 . 0}$ & Excellent \\
\hline
\end{tabular}

1.4. Test methods for quantitative assessment of UV protection of textiles

\subsubsection{In Vitro}

Direct and diffuse UV transmittance through a fabric is the crucial factor determining the UV protection of textiles. Radiometric UV transmission tests use a broadband UV light source filtered for UV-B or combined UV-A and UV-B spectral regions to illuminate a fabric sample.

\subsubsection{In Vivo}

With human volunteers, use of the sun as the UV source is impracticable to test the UPF of fabrics. Generally, xenon arc 


\section{International Journal of Science and Research (IJSR) \\ ISSN (Online): 2319-7064}

Index Copernicus Value (2013): 6.14 | Impact Factor (2014): 5.611

solar simulators are used, with filters to absorb wavelengths below $290 \mathrm{~nm}$ and to reduce visible and infrared radiation. The most frequently performed in vivo test method is in vivo confirmation of the UPFs measured in vitro. Based on skin photo type, MED is determined using incremental UV-B doses on the upper back of a subject and is read after 24 hours. To measure the MED of protected skin, a textile is placed over the skin on the other side of the back. The incremental UVB doses for determining the MED of unprotected skin are multiplied by the UPF determined in vitro, with the product being the incremental UV-B doses for MED testing of the protected skin. The in vivo and in vitro methods are in agreement if the ratio of the MED of protected skin to the MED of unprotected skin results in the original in vitro UPF. [4], [11]

\subsection{Textiles as protection from ultraviolet radiation}

Because fabric is composed of fibers that can absorb, reflect or scatter radiant energy, it has the ability to absorb and/or block most of the incident radiant energy and prevent it from reaching the skin. Fig (2) is a schematic representation of the different ways a fabric can prevent UV radiation from coming into contact with the skin. However, a fabric's ability to block UVR is dependent on several parameters [12], [13], [14].

The construction of woven and knitted fabrics and the fiber types have a great influence on protection from ultraviolet transmittance. The ultraviolet protection factor (UPF) of textiles depends on their construction, the spaces between the yarns, their fiber types, the color, the textile impregnation, and the presence of optical brighteners and ultraviolet absorbers [2].

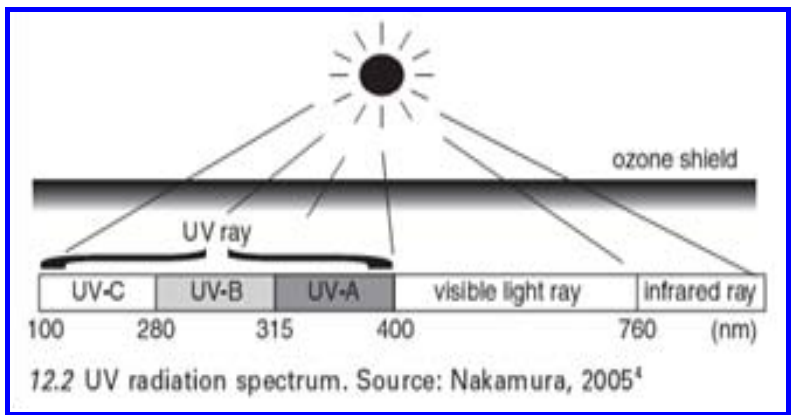

Figure 1: UV radiation spectrum [13]

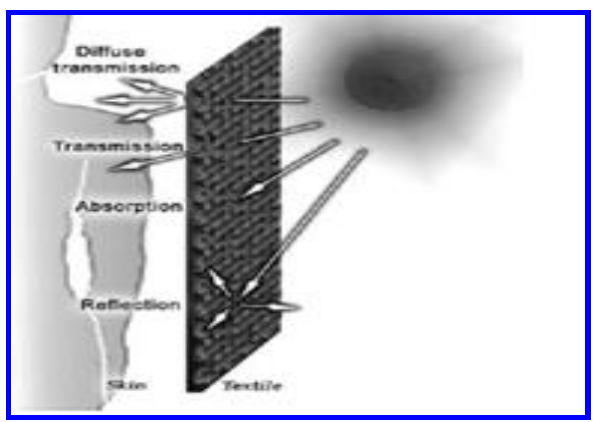

Figure 2: Schematic representation of a textile as a barrier to UV Radiation [12]

\subsection{Parameters affecting UV protection of textile}

\subsubsection{Material and Composition}

- Different fabrics absorb UV radiation at different levels. Most cotton or cotton/polyester blend fabrics provide protection equal to about UPF 20 (which is about 95\% protection from UV radiation).

- Comparison of the UPF of different types of material is difficult and possible only in limited situations. This is because certain production steps (dyeing and finishing) vary based on the material, resulting in a comparison of the "material-color-finish" combination and not of the material itself. In accordance with most studies, the type of fiber used to construct a textile can have a substantial effect on the UPF, especially for white and non-dyed fabrics [15]. Polyester usually has good UV blocking properties, as this fabric allows relatively little UV-B transmission, probably because of the large conjugated system of polymer chains. Polyester (or polyester blends) may be the most suitable fabric type for UV protective garments. However, its permeability for wavelengths in the UV-A range is frequently higher than that of other fiber types.

\subsubsection{Porosity, Weight, Thickness, and Weave density}

- The closer the fabrics' weave, the higher the UV radiation protection, because the fibers of tightly woven fabrics are closer together, less UV radiation is able to pass through to the skin. To understand the relationship between UV transmission and fabric structure, an "ideal" fabric is proposed, in which the yarns are completely opaque to UV radiation and the holes or spaces between the yarns are very small. Ultraviolet transmission through ideal fabric is related to the cover factor of the fabric with opaque yarns as follows: \% UV transmission=100/(100-cover factor).\% [11], [16].

\subsubsection{Finishing \& Color and UV absorbers}

- Many dyes absorb UV radiation. Darker colors (black, navy, dark red) of the same fabric type will absorb UV radiation more than light pastel shades (white, sky blue, light green). [17].

- The dyes used to color a textile can affect the UV protectiveness of a fabric, depending on the position and intensity of the UV wavelength absorption bands of the dyes and the concentration of the dyes in the textile. However, particular hue dyes can vary considerably in the degree of UV protectiveness because of individual transmission and absorption characteristics. [11], [18].

\subsubsection{Stretch}

- Stretching a textile causes an increase in fabric porosity, with a consequent decrease in UPF. [11], [16].

\subsubsection{Wetness}

- When textiles become wet, by air hydration, perspiration, or water, UV transmission through the fabric can significantly change, with a marked reduction of UPF observed for textiles made from cotton and cotton blends. One explanation for this is that the presence of water in the 


\section{International Journal of Science and Research (IJSR) \\ ISSN (Online): 2319-7064}

Index Copernicus Value (2013): 6.14 | Impact Factor (2014): 5.611

interstices of a fabric reduces optical scattering effects and, hence, increases UV transmission of the textile. [11], [19].

\section{Experimental Work}

\subsection{Limitation of the study}

- Materials : Cotton and polyester Microfiber

- Circular Weft knitting machines in manufacturing of fabrics

\subsection{The purpose from using Cotton and polyester} Microfiber

The theoretical study has shown that:

- Cotton is an appropriate material for the production of textiles for different fields. It has great moisture absorption ability [20] and comfortable ability. People with sensitive skin need a very comfortable fabric in their clothes, so we choose cotton fabric in this study especially because it is known that the cotton fabrics are the best in comfortable ability.

- Polyester Microfiber yarn usually has very good UV blocking properties more than polyester multifilament.

\subsection{Specification of the manufactured fabrics}

The researchers designed and manufactured 24 wefts knitted samples with different variables in constructions, those variables are:

- Knitted fabric structure (Rib, Interlock and Single jersey structures)

- $\quad$ Different materials (Cotton and Polyester Microfiber).

- Different stitch length (Three levels of Yarn Tension).

- Yarn count. (Table (3) shows the specifications of manufacturing fabrics.)

\subsection{Fabric Testing}

The manufacturing samples are tests to determine:

- Number of Wales per cm (W)

- Number of Courses per $\mathrm{cm}(\mathrm{C})$

- Stitch length (L)

- Weight test (Mass per unit area)

- Thickness Test

- The ultraviolet transmission for fabric, and calculated the UPF

- Calculated (K) Tightness factor

- Calculated(S) fabric stitch density $/ \mathrm{cm}^{2}$

\subsection{Calculations}

\subsubsection{Tightness factors}

The tightness factor $\mathrm{K}$ of a knitted fabric is defined as the ratio of the fabric area covered by the yarn to the total fabric area. It is regarded as a measure of looseness or tightness of the structure, and influences dimensions such as the length, width, and thickness and many other fabric characteristics. [27].

\section{Tests results}

Table (3) shows the tests resulted for manufactured samples

Table 3: Shows the specifications of the manufacturing fabrics

\begin{tabular}{|c|c|c|c|c|c|}
\hline $\begin{array}{c}\text { Sample } \\
\text { No. }\end{array}$ & Material & Yarn count & Structure & gauge & $\begin{array}{c}\text { Yarn tension } \\
\text { level }\end{array}$ \\
\hline 1 & \multirow{3}{*}{ Cotton } & \multirow{3}{*}{$\begin{array}{c}30 / 1 \mathrm{Ne} \\
\text { Combed / } \\
\text { Giza } 86\end{array}$} & \multirow{3}{*}{ Rib } & \multirow{3}{*}{20} & High \\
\hline 2 & & & & & Medium \\
\hline 3 & & & & & Low \\
\hline 4 & \multirow{3}{*}{ Cotton } & \multirow{3}{*}{$\begin{array}{c}30 / 1 \mathrm{Ne} \\
\text { Combed / } \\
\text { Giza } 86\end{array}$} & \multirow{3}{*}{ Interlock } & \multirow{3}{*}{20} & High \\
\hline 5 & & & & & Medium \\
\hline 6 & & & & & Low \\
\hline 7 & \multirow{3}{*}{ Cotton } & \multirow{3}{*}{$\begin{array}{c}30 / 1 \mathrm{Ne} \\
\text { Combed / } \\
\text { Giza } 86\end{array}$} & \multirow{3}{*}{$\begin{array}{l}\text { Single } \\
\text { Jersey }\end{array}$} & \multirow{3}{*}{20} & High \\
\hline 8 & & & & & Medium \\
\hline 9 & & & & & Low \\
\hline 10 & \multirow{3}{*}{$\begin{array}{l}\text { Polyester } \\
\text { Microfiber }\end{array}$} & \multirow{3}{*}{$\begin{array}{c}150 / 288 \\
\text { Denier }\end{array}$} & \multirow{3}{*}{ Rib } & \multirow{3}{*}{20} & High \\
\hline 11 & & & & & Medium \\
\hline 12 & & & & & Low \\
\hline 13 & \multirow{3}{*}{$\begin{array}{l}\text { Polyester } \\
\text { Microfiber }\end{array}$} & \multirow{3}{*}{$\begin{array}{c}150 / 288 \\
\text { Denier }\end{array}$} & \multirow{3}{*}{ Interlock } & \multirow{3}{*}{20} & High \\
\hline 14 & & & & & Medium \\
\hline 15 & & & & & Low \\
\hline 16 & \multirow{3}{*}{$\begin{array}{l}\text { Polyester } \\
\text { Microfiber }\end{array}$} & \multirow{3}{*}{$\begin{array}{l}150 / 288 \\
\text { Denier }\end{array}$} & \multirow{3}{*}{$\begin{array}{l}\text { Single } \\
\text { jersey }\end{array}$} & \multirow{3}{*}{20} & High \\
\hline 17 & & & & & Medium \\
\hline 18 & & & & & Low \\
\hline
\end{tabular}

Table 4: Shows the tests and standard test methods

\begin{tabular}{|c|c|c|}
\hline No. & Properties & Standard Test Methods \\
\hline 1 & Stitch length & (BS5441)[21] \\
\hline 2 & Stitch density & (ASTM, D3887)[22]. \\
\hline 3 & $\begin{array}{c}\text { Mass per unit area (Weight } \\
\text { test) }\end{array}$ & (ASTM, D3776)[23] \\
\hline 4 & Thickness Test & (ASTM, D1777) [24] \\
\hline 5 & $\begin{array}{c}\text { The transmission of } \\
\text { ultraviolet radiation (UV-R) } \\
\text { through a specimen }\end{array}$ & $\begin{array}{c}\text { ASTM-D6603-00) [25], } \\
\text { A26]. }\end{array}$ \\
\hline
\end{tabular}

\subsection{Data Analysis and Discussion}

Three different fabric Structures Types, two different Materials and three levels of Yarn Tension with the same machine gauge and same yarn count effects on different fabrics' physical properties and Ultraviolet protection properties .

\subsubsection{The effect of Structures types on fabric s' Ultraviolet} protection properties

Charts of influence of Structures types on fabric s' UPF show that: (fig.3)

- Interlock structure give the highest ultraviolet protective property, this can be relate to its' high thickness and high stitch density and tightness factor, Interlock structure is a double layers from single jersey fabrics this give it a high thickness which prevent UV rays transmission to the skin.

- Single jersey give the lower ultraviolet protective property, it give a very low UPF which isn't accepted as a protective fabrics because of its lowest thickness and its opened pores. 


\section{International Journal of Science and Research (IJSR) \\ ISSN (Online): 2319-7064}

Index Copernicus Value (2013): 6.14 | Impact Factor (2014): 5.611

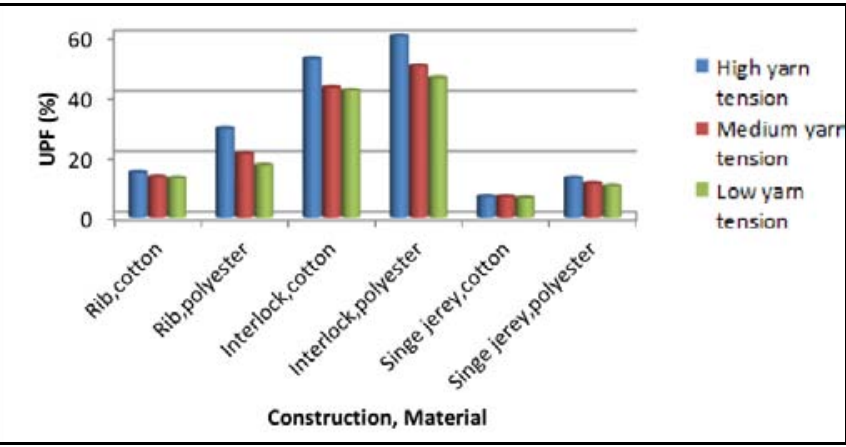

Figure 3: Shows the Influence of Different weft knitting Structures types, Different yarn tension level and different materials on fabric s' UPF

Table 5: Shows tests results for manufactured samples

\begin{tabular}{|c|c|c|c|c|c|c|c|c|}
\hline \multirow[b]{2}{*}{$\begin{array}{l}\text { S. } \\
\text { No. }\end{array}$} & \multicolumn{3}{|c|}{ Stitches Density } & \multirow[b]{2}{*}{ 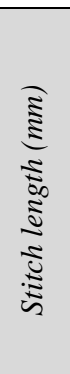 } & \multirow[b]{2}{*}{ 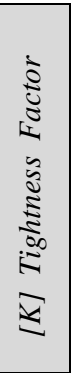 } & \multirow[b]{2}{*}{ 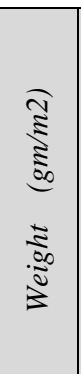 } & \multirow[b]{2}{*}{ 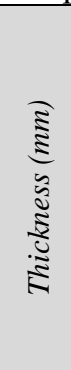 } & \multirow[b]{2}{*}{$\frac{5}{2}$} \\
\hline & $\sum \frac{\tilde{\Xi}}{\tilde{\Xi}}$ & Uิ & 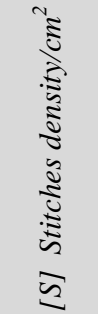 & & & & & \\
\hline 1 & .05 & 17.56 & 387.13 & 2.58 & 17.2 & 82.3 & 0.76 & 1 \\
\hline 2 & 22.44 & 17.01 & 31.67 & 2.61 & 17.0 & 181 & 0.784 & 13.25 \\
\hline 3 & .60 & 16.61 & 375.45 & 2.66 & 16.7 & 180 & 0.786 & 12.91 \\
\hline 4 & 2 & 13.30 & 323.58 & 3.8 & 23.4 & 240 & 1.26 & 52.27 \\
\hline 5 & & & 310.5 & 3.99 & 22.2 & 233.5 & 1.28 & 42.88 \\
\hline \begin{tabular}{|l|}
6 \\
\end{tabular} & 43 & 9 & 299.89 & 4.1 & 21.6 & 227 & 1.31 & 41.88 \\
\hline \begin{tabular}{|l|}
7 \\
\end{tabular} & 10.83 & 2.44 & 42.96 & 2.85 & 15.6 & 132.7 & 0.62 & 6.8 \\
\hline 8 & 11.55 & 19.75 & 28.04 & 2.9 & 15.3 & 130 & 0.62 & 6.76 \\
\hline \begin{tabular}{|l|}
9 \\
\end{tabular} & 1 & .05 & 208.82 & 3.03 & 14.6 & 128 & 0.63 & 6.38 \\
\hline 10 & & 7.32 & 440.98 & 2.58 & 15.8 & 178.9 & 0.756 & 35 \\
\hline 11 & & & 77 & 2.89 & 14.1 & 169.2 & 0.784 & 21.09 \\
\hline 12 & & & 320.97 & 3.16 & 12.9 & 157.4 & 0.786 & 17.08 \\
\hline 13 & & 2 & 99 & 3.27 & 24.9 & 192.4 & 0.89 & 59.81 \\
\hline 14 & 2 & 14.43 & 371.17 & 3.28 & 24.9 & 189.8 & 0.9 & 49.92 \\
\hline 15 & 67 & .33 & 29 & 3.72 & 21.9 & 171.5 & 0.99 & 46 \\
\hline 16 & 14.76 & 7 & 308.06 & 2.75 & 14.8 & 127.6 & 0.59 & 12.94 \\
\hline 11 & & & 275.9 & 2.92 & $\begin{array}{l}13.9 \\
\end{array}$ & 127.4 & 0.6 & 11.16 \\
\hline 10 & 15.94 & 17.72 & 279 & 3.04 & 13.4 & 119.2 & 0.65 & 10.28 \\
\hline
\end{tabular}

\subsubsection{Relationship between Different Parameters of Weft} Knitting Fabrics and Fabric s' UPF

The value of the Correlation coefficient indicates that there are:

- A high positive relationship between UPF and tightness factor in cotton fabrics with high, medium and low yarn tension levels. (Fig. 4).

- A low positive relationship between UPF and stitch density in cotton fabrics with all three yarn tension levels, So stitch density isn't the only indicator to the UPF factor of the sample because samples have different structures, so other factors has a higher effect like tightness and thickness. (Fig. $5)$.
- A high positive relationship between UPF and thickness in cotton with high, medium and low yarn tension levels. (Fig. $6)$.

- A high positive relationship between UPF and tightness factor in microfiber polyester fabrics with high, medium and low yarn tension levels. (Fig. 7).

- A medium positive relationship between UPF and stitch density in polyester microfiber fabrics with high and medium yarn tension levels. (Fig. 8).

- A low positive relationship between UPF and stitch density in polyester microfiber fabrics with low yarn tension levels.

- The value of the Correlation coefficient indicate that there are a high positive relationship between UPF and thickness in polyester microfiber fabrics with high, medium and low yarn tension levels. (Fig. 9).

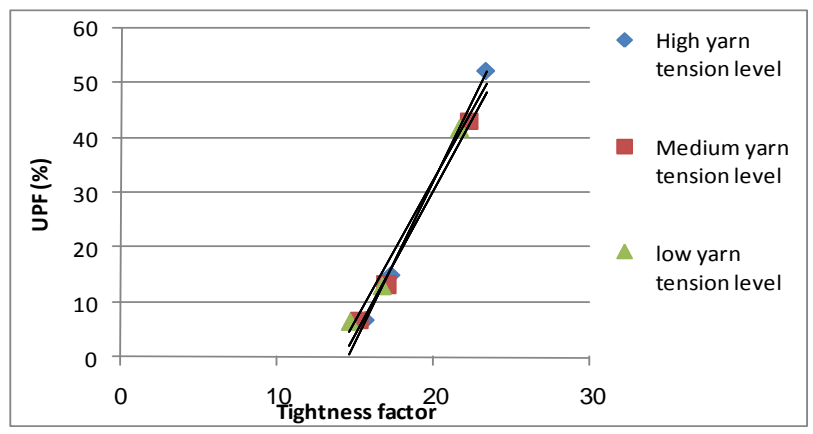

Figure 4: Correlation between Different Structures types' Tightness factor, Different yarn tension level on cotton fabric s' UPF

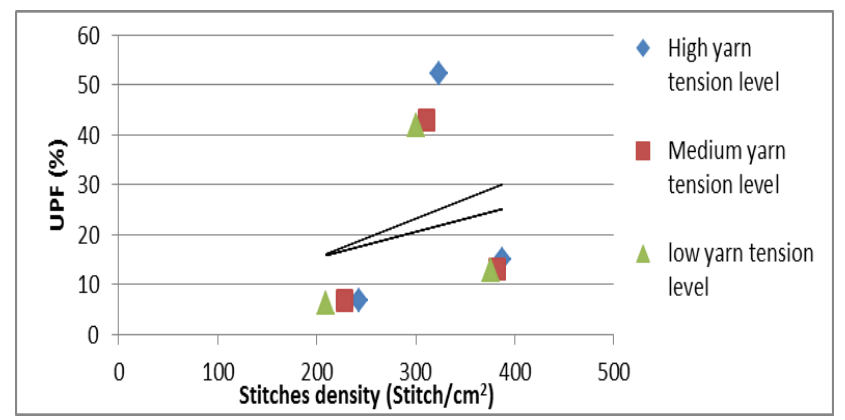

Figure 5: Correlation between Different Structures types' Stitches densities, Different yarn tension level on cotton fabric s' UPF

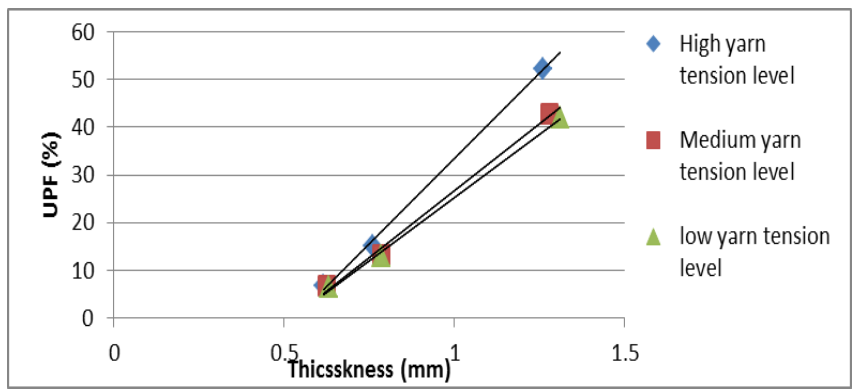

Figure 6: Correlation between Different Structures thickness, Different yarn tension level on cotton fabric s' UPF

Volume 4 Issue 12, December 2015 


\section{International Journal of Science and Research (IJSR)}

ISSN (Online): 2319-7064

Index Copernicus Value (2013): 6.14 | Impact Factor (2014): 5.611

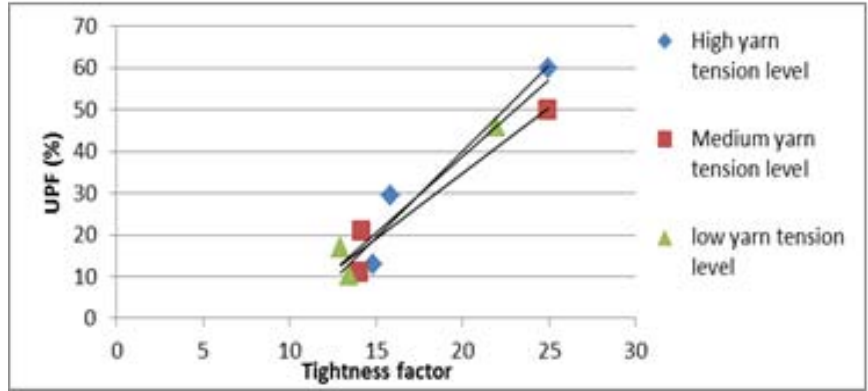

Figure 7: Correlation between Different Structures types' Tightness factor, Different yarn tension level on polyester microfiber fabric s' UPF

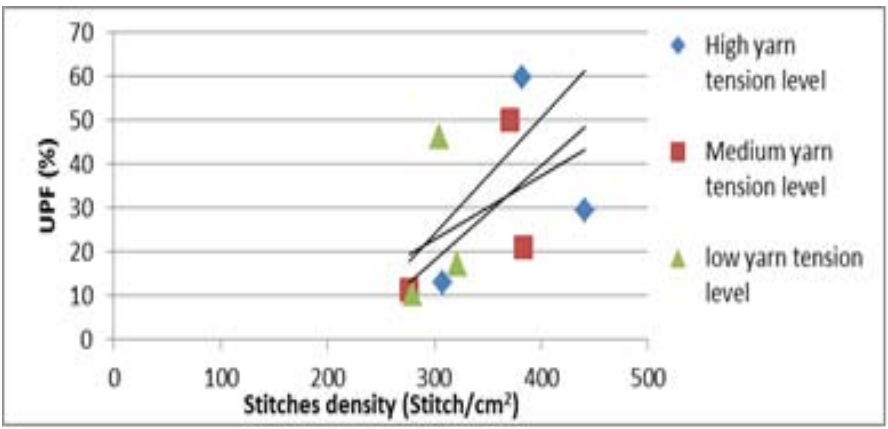

Figure 8: Correlation between Different Structures types' Stitches densities, Different yarn tension level on polyester microfiber fabric s' UPF

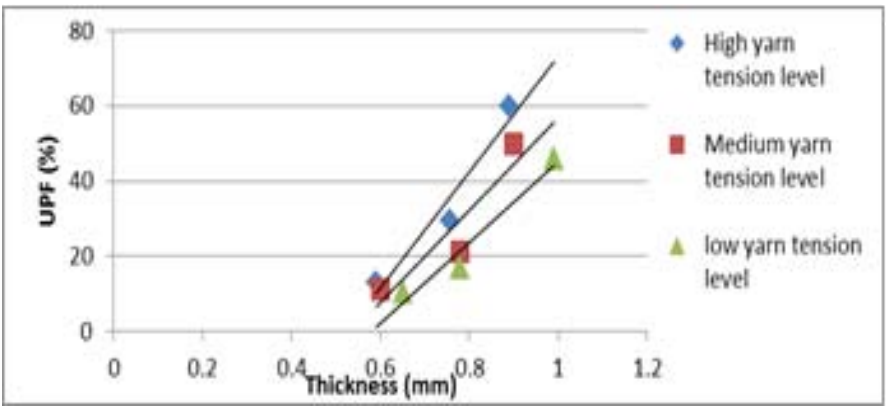

Figure 9: Correlation between Different Structures thickness, Different yarn tension level on polyester microfiber fabric s' and fabric UPF

\section{Conclusion}

a) Effect of different structure type on UV protection properties:

Samples with Interlock structure gave the highest ultraviolet protection (UPF), followed by sample with Rib structure then samples with Single jersey which gave the lowest ultraviolet protection (UPF).

b) Effect of different yarn tension level on UV protection properties:

The highest yarn tension level gave the highest ultraviolet protective fabrics followed by the medium yarn tension level then the lowest yarn tension level which gave the lowest ultraviolet protective fabrics. c) Effect of different fabrics' material on UV protection properties:

Polyester microfiber fabrics gave better protection against UV radiations than Cotton fabrics with equal yarn count and equal machine gauge.

\section{References}

[1] Julian M. Menter , Kathryn L. Hatch "Clothing as Solar Radiation Protection" Textiles and the Skin. Curr Probl Dermatol. Basel, Karger, Vol. 31, 2003, page 5063.

[2] Arshia Hussain , Shahnaz Jahan "Textiles protection against ultraviolet radiation" The Indian textile Journal, June 2010.

[3] Eckhardt, C., and Rohwer, H."UV Protector for Cotton Fabrics", Textile Chem. Color. Am. Dyest. Rep. 32 (4), 2000, Page 21-23.

[4] Julian M. Menter , Kathryn L. Hatch "Clothing as Solar Radiation Protection" Textiles and the Skin. Curr Probl Dermatol. Basel, Karger, Vol. 31, 2003, page 5063.

[5] W. Czajkowski , Joanna Paluszkiewicz , Roland Stolarski ,MariolaKaz'mierska, Edyta Grzesiak "Synthesis of reactive UV absorbers, derivatives of monochlorotriazine, for improvement in protecting properties of cellulose fabrics" Dyes and Pigments Journal ,Vol. 71,2006, Page 224-230.

[6] James R.Liffering" Phototrauma prevention" Wilderness and Environmental Medicine, 12,2001, Page 195-200.

[7] D. Saravanan "UV PROTECTION TEXTILE MATERIALS",AUTEX Research Journal, Vol. 7, No 1, March 2007, Page 53-62.

[8] DermNet NZ "Sun protective clothing" Created 2006. Last updated 15 Dec 2007. (C) 2008NZDS. .http://www.dermnetnz.org/treatments/sun-protectiveclothing.html

[9] Inés Algaba, Ascension Riva and Montserrat Pepio" Modelization of the Influence of the Wearing Conditions of the Garments on the Ultraviolet Protection Factor", Textile Research Journal ,Vol. 77(11),.2007 , Page 826836

[10] Australian Radiation Protection \& Nuclear Safety Agency (ARPANSA). Resource Guide for UV Products. Yallambie ARPANSA 2003.

[11] Capjack, L., Kerr ,N., Davis, S., Fedosejevs, R., Hatch, K.L. and N.L. "Protection of humans from ultraviolet radiation through the use of textiles: A Review.", Family and Consumer Science Research Journal, Vol.23(2) , 1994, Page 198-218

[12] A.K.SARKAR "Textile for UV Protection" Wood head publishing in textiles, Textile for protection, Page 355377

[13] L. Hunter" Ultraviolet protection of fabrics and garments" Wood head publishing in textiles , Engineering apparel fabrics and garments, Page 309-334

[14] M Belkin, et al "Protection Against Exposure to Ultraviolet Radiation", World Health Organization, 
United Nations Environment Programme, August 1994. [http://www.who.int/uv/publications/proUVrad.pdf]

[15] Klaus Hoffmann"Defined UV protection by apparel textile", ARCH DERMATOL, Vol. 137, Aug 2001, Page 1089-1094.

[16] Mike Pailthorpe" Apparel textiles and sun protection: a marketing opportunity or a quality control nightmare" Mutation Research Journal, 422, 1998, Page 175-183.

[17] Gwendolyn Hustyedt and Patricia Cox Crews " The Ultraviolet Protection Factor of Naturalally-pigmented Cotton" The Journal of cotton Science ,Vol. 9,2005, Page 47-55.

[18] Cheryl A. Wilson, Nicola K. Bevin, Raechel M. Laing and Brian E. Nive "Solar Protection Effect of Selected Fabric and Use Characteristics on Ultraviolet Transmission", Textile Research Journal ,Vol. 78(2),.2008 , Page 95-104

[19] C. A. Wilson and A. V. Parisi "Simulated Wear and Laboratory Testing-otection from Solar Erythemal Ultraviolet Radiation", Textile Research Journal ,Vol. 76(3),.2006, Page 216-225

[20] Marija Gorensek and Petra Recelj " Nanosilver Functionalized Cotton Fabric ", Textile Research Journal. Vol.77( 3), 2007. Page 138-141.

[21] BS5441, British standard methods of test for knitted fabrics

[22] ASTM, D3887 Standard Specification for Tolerances for Knitted Fabric

[23] ASTM D3776 / (2013), Standard Test Methods for Mass per Unit Area (Weight) of Fabric, American Society for Testing and Materials, West Conshohocken, PA, USA.

[24] ASTM D1777 - 96(2011), Standard Test Method for Thickness of Textile Materials.

[25] Torres Woolley, Petra G. Buettner and John Lowe" Predictors of sun protection in northern Australian men with a history of nonmelanoma skin cancer" Preventive Medicine Journal ,Vol. 39,2004, Page 300-307.

[26] ASTM-D6603-00, Standard Guide for Labeling of UVProtective Textiles.

[27] Subhash C Anand"Technical fabric structures 2.Knitted fabrics", Handbook of technical textiles. 